tion of the priniciple that the Medical Superintendent is Chief Officer in so far as medical policy is concerned and the Chief Male Nurse and Matron remaining responsible to him". Later, in discussing the Medical Staff Committee, "It should be pointed out that the Medical Superintendent, as Chairman, has more authority than the elected Chairman". Most psychiatrists would regard this authoritarian policy to be disastrous in any hospital.

Chapter 14 discusses Out-patient and domiciliary facilities and gives figures that the Consultants at one hospital spend $40 \frac{1}{2}$ out of 64 sessions in the community and the junior staff spend $24 \frac{1}{2}$ sessions out of 47 away from the hospital. This must give rise to concern about the quantity and quality of the care given to In-patients and the main hospital. Perhaps economy has forced a group community approach to mental hospital care and one feels the patients are placed in a highly organised, humane, 'conveyor belt' system, where the patients individual needs are stressed only too little. The importance of training junior medical staff in a psychotherapeutic approach is scarcely mentioned.

The relationship of the psychiatric and community services are discussed in several articles. So often both are involved in treating the same family constellation that it is clearly wrong for the services not to be unified, particularly as the community services are not headed by a psychiatrist. Other administrative anomalies are mentioned in Chapter 15 where economic disincentives to employment are discussed and in Chapter 18 where the author was only able to provide home treatment for patients by overcoming the most rigid community bureaucracy.

Chapter 24 discusses institutional accommodation of old people; one notes that $1 / 3$ of patients have nothing other than a bed and $3 / 5$ are cared for in dismal surroundings with inadequate furniture, and it is not surprising also to read that an astonishingly large number of physical and psychiatric handicaps are tolerated at home and not even brought to the notice of the General Practitioner.

The book gives a faithful working picture of the best of the psychiatric services in this period of the history of the National Health Service. There is an abundance of enthusiasm and endeavour, though in geriatrics where the pioneer spirit has not been so much felt, the situation is a slur upon our community. It is necessary for a standard of care to be defined and some supervision to ensure that it is attained, as is mentioned in Chapters 2 and 3. All psychiatrists, particularly those involved in the mental hospital field would find much of interest in this book and it is hoped that the price of $50 /-$ will not discourage the book from reaching a wide public.

\section{The Neuroendocrine Control of Adaptation}

By K. Lissak and E. Endroczi. International Series of Monognaphs in Pure and Applied Biology, Modern Trends in Physiological Sciences Vol. 25. Pp. xii +180 illustrated. Oxford, London, etc.: Pergamon Press. 1965. 70s.

This book sets out to give a comprehensive and critical account of the way in which the central nervous system controls those endocrine glands concerned with the adaptation of an animal to its environment. It deals in detail with the regulation and function of the adrenal cortex, the influence of the brain on the pituitary, and the inter-relationships between the adrenal cortex and the gonads. The authors have themselves done a great deal of work in this field, both in experimental animals and in man, and this book contains a wealth of welldocumented experimental evidence which is marshalled in a convincing manner. Their observations on the presence of more polar stercids than cortisol and corticosterone in the adrenal vein blood of dogs and cats are particularly interesting, since in some animals they found that these unknown steroids amounted to as much as $80 \%$ of the total corticosteroid content. Similar substances have been found in trace amounts by other workers in the adrenal vein blood of man. Neither the physiological function nor the chemical structure of these more polar steroids has yet been determined, but the authors found that they possessed high lympholytic but low glucocorticoid activity in adrenalectomised rats.

There is a most interesting chapter on the effects of various corticosteroids on the excitability of the central nervous system in which the authors discuss the possible role of qualitative changes in adrenal steroid secretion in the aetiology of epilepsy and of schizophrenia. For example, they were able to deteot the presence of five unoonjugated $\triangle^{4}$-3-keto-corticosteroids in the urine of aggressive untreated schizophrenics which were not present in the urine of depressed schizophrenic patients or of normal individuals.

One minor drawback to the book is that the survey of the literature on which the work is based was concluded in 1960. This delay in publication is a consequence of its translation, for it was originally published in German as Die neuroendocrine Steuerung der Adaptationstätigkeit. It has, however, been very skilfully translated and can be recommended to all serious students of endocrinology.

\section{A Diagnostic Approach to Chest Diseases- Differential Diagnoses Based on Roentgenographic Patterns}

By Glen A. LiLlington and ROBERT W. JAMPLis, Baltimore: Williams and Wilkins. Edinburgh and London: E. \& S. Livingstone. 1965. £6 16s.

This book is based upon a premise stated in the author's introduction 'An analysis of the chest roentgenogram is the logical starting point in the differential diagnosis of pulmonary disease as it is encountered in the clinical environment.' Nevertheless, the book is much more than a text of chest radiology. 'It is intended to serve as a practical guide in the determination of the correct diagnosis in the patient with bronchopulmonary diseases'.

There are two serious disadvantages to this method of presentation. First, it excludes any consideration of the patient in terms of disordered function-it is entirely a static concept of disease. (There are of course several textbooks which cover this aspect of chest disease very adequately notably the superb 'Respiratory function in disease' by Bates and Christie). Second, the method necessarily involves a considerable element of repetition. Many diseases have to be included repeatedly under the different radiological parterns. This tends to make for tedious reading in parts and because it demands considerable compression leads to the omission of important detail in places. For example: in the opening chapter, sarcoidosis is not given as a cause of erythema nodosum though it is mentioned in the chapter on 
'Bilateral hilar enlargement'; though there are six references to Caplan's syndrome it is not included with progressive massive fibrosis in the chapter 'Bilateral perihilar shadows'.

The work is full of useful information: there are many useful references and the illustrations are generally of good quality. However, there are some important omisions. For example, there is no reference to the role and diagnostic significance of precipitating antibodies in diseases such as byssinosis caused by vegetable dusts, aspergillosis caused by fungi, or to Farmer's Lung caused by actinomycetes. The statement 'progressive massive fibrosis in silicosis and in coal workers' pneumoconiosis is usually due to secondary tuberculosis infections' needs qualification in the light of recent work. The statement 'mediastinal adenopathy in adult life is rarely, if ever, due to tuberculosis' is certainly not applicable to the disease as it is seen in coloured races. No mention is made of carcinomatous neuro-myopathy in the list of neurological complications of pulmonary diseases.

All in all, then, this book, though a fine attempt to achieve a very difficult target, can only be considered an incomplete suocess.

\section{NEW EDITIONS}

\section{Diseases of Women}

By Ten Teachers under the direction of $F$. W. ROQUES. Eleventh edition, edited by $F$. W. Roques, S. G. Clayton and T. L. T. Lewis. Pp. viii +576 , illustrated. London: Edward Arnold. 1964. 50s.

It is always a pleasure to renew acquaintance with an old friend and, in reading the eleventh edition of this book, the reviewer is again struck by the consistently high standard achieved. Editorial and contributor changes have taken place but the character of the book remains unaltered. There have been additions and re-arrangements and two new chapters have been added. The first deals with the determination of sex and the second with radiotherapy in gynaezology. The chapter on neurosis in relation to pelvic disorders has been replaced by a section on psychosomatic disorders in gynaeoology and this chapter, although brief, will repay careful reading by the student on account of the truth contained in its pages.

There is brief description of vaginal cytology in the normal woman and also in malignant disease and the use of cytotoxic drugs in the latter conditions is also included.

Reasonably priced, well printed and illustrated, this book is a model of clarity and will continue to remain one of the best student textbooks of gynaecology.
Guide to House Surgeons in the Surgical Units

G. J. FraENKEL and J. LuDBRook. Third Edition

Pp. 99. London: William Heinemann. 1964 12 s. $6 \mathrm{~d}$.

This small pocketable book of 99 pages by Professor Fraenkel of Otago University and $\mathrm{J}$ Ludbrook was first published in New Zealand in 1961 and now in its third edition is available in this country.

It aims to standardise various aspects of the investigations and management of patients sufferingס from a variety of common surgical conditions.

This admirable little book is packed with helpfulos advice and information. Selwyn Taylor in his fore- $\overrightarrow{0}$ word wrote that he would have liked to possess. this book when he was a house surgeon. The guide will save much time and embarrassment to the house surgeon starting on his first surgical appointment.

\section{Diseases of the Ear, Nose and Throat.}

Edited by W. G. SCOTT-BROWN, JOHN BALlANTYNE and JoHN Groves. 2nd Edition. In two volumes. Pp. 1,620, illustrated. London: Butterworths. 1965. $£ 17.15$ s.0d. per set.

The first edition of this book, published in 1952W under the editorship of W. G. Scott-Brown, waso soon acclaimed as a textbook and work of reference for the postgraduate student and general practitioner.

The second edition now available maintains the very high standard of the first. There has been greatow resurgence of ear, nose and throat surgery since the War and the last fifteen years have seen advan\&s $\overrightarrow{0}$ on all fronts. The editors have performed sng excellent and undoubtedly arduous task in bringing these advances within the pages of this book. 9t? necessitated a good deal of pruning and re-writings of the first edition-the second promises to be as popular, if not more so.

There are thirty-four contributors-mostly leaders@ in British otolaryngology. As to be expected not all reach the same high standard. One or two chapters $\vec{\Rightarrow}$ could with benefit be shortened. Praise is merited? for the sections on physiology and those dealing with recent work on the treatment of cancer.

The work is up-to-date. Some of the material? included appeared in the ISpecialist journals aso recently as late 1964. Omissions are few (for? example the less common neuralgias affecting theo face). A chapter on headaches could with advantage be incorporated.

The index is comprehensive and there is an innovation in a symptom index which covers the more oommon conditions.

The photographs and illustrations, many in colour, $D$ are good and the $X$-ray reproductions clear. The print, layout and paper are excellent.

This book is highly recommended to the post- $N$ graduate student and practising ear, nose and throat surgeon. The general practitioner would find here an up-to-date and clear reference book. 